\title{
First experimental evidence for the preferential stabilization of the natural $D$ - over the nonnatural L-configuration in nucleic acids
}

\author{
SARAH BOLIK, ${ }^{1}$ MICHAEL RÜBHAUSEN, ${ }^{1}$ STEPHAN BINDER, ${ }^{1}$ BENJAMIN SCHULZ, ${ }^{1}$ MARKUS PERBANDT, ${ }^{2}$ \\ NICOLAY GENOV, ${ }^{3}$ VOLKER ERDMANN, ${ }^{4}$ SVEN KLUSSMANN,${ }^{5}$ and CHRISTIAN BETZEL ${ }^{2}$ \\ ${ }^{1}$ Institute of Applied Physics, University of Hamburg, 20355 Hamburg, Germany \\ ${ }^{2}$ Institute of Biochemistry and Molecular Biology, University of Hamburg, 22603 Hamburg, Germany \\ ${ }^{3}$ Institute of Organic Chemistry, Bulgarian Academy of Sciences, Sofia 1113, Bulgaria \\ ${ }^{4}$ Institute of Biochemistry, Free University of Berlin, D-14195 Berlin, Germany \\ ${ }^{5}$ NOXXON Pharma AG, 10589 Berlin, Germany
}

\begin{abstract}
The homochirality of biomolecules is a prerequisite for the origin and evolution of terrestrial life. The unique selection of D-monosaccharides, in particular, D-ribose in RNA and D-deoxyribose in DNA, leads to the construction of proteins by L-amino acids. This points to the exclusive role of stereoselectivity in the most important physiological processes. So far, there is no experimental confirmation for the theoretical calculations of the energy differences between enantiomers used for the explanation of the stereoselection of biomolecules. Therefore, the question of why nature prefers one configuration over the other still lacks a definitive answer. Here, we present the first experimental evidence that the D-enantiomer of RNA has a different electronic structure compared to the corresponding L-enantiomer. When varying the incident photon energy of the ultraviolet Raman probe across $5 \mathrm{eV}$, D- and L-isomers of the RNA duplex with the sequence [r(CUGGGCGG).r(CCGCCUGG)] show differences in the intensity of the vibrational modes with energies of $124.0 \mathrm{meV}$ to $210.8 \mathrm{meV}$. The intensity difference of these vibrational modes can be traced back to energy differences in the electronic levels of D- and L-RNA leading to the preferential stabilization of the naturally occurring D-configuration of RNA over the L-configuration.
\end{abstract}

Keywords: homochirality; RNA stabilization; Raman spectroscopy; enantiomer; stereoselection

\section{INTRODUCTION}

The homochirality of biomolecules is directly connected to the origin and evolution of terrestrial life. However, the reasons for the symmetry breaking and preference of one stereoisomer over another in nature still continues to be an unanswered question.

Chirality is not only an inherent property of matter (Davankov 2006), but also a common property of all informational and functional biomolecules: DNA, RNA, proteins, and carbohydrates. L- $\alpha$-amino acids are chemically related to D-sugars. This was demonstrated by the transformation of D-glucosamine to L-alanine (Wolfrom

Reprint requests to: Christian Betzel, Institute of Biochemistry and Molecular Biology, University of Hamburg, 22603 Hamburg, Germany; e-mail: Betzel@unisgil.desy.de; fax: 494089984747.

Article published online ahead of print. Article and publication date are at http://www.rnajournal.org/cgi/doi/10.1261/rna.564507. et al. 1949). Moreover, amino acids catalyze asymmetric de novo synthesis of hexoses through cross-aldol reactions that proceed with high stereoselectivity (Cordova et al. $2005 a, b)$. In this way, an asymmetric synthesis of deoxysugars with $>99 \%$ enantiomeric excess has been achieved (Cordova et al. 2005a). It is evident that the building blocks of the naturally occurring proteins, carbohydrates, and nucleic acids are structurally related.

Giant biomolecules are involved in processes that are essential for living organisms and outline the extreme importance of homochirality for life. In particular, RNA plays an intermediate function between DNA and proteins. RNA possesses functions typical for both types of biopolymers, as an informational carrier and biocatalyst (Zaug and Cech 1986; Cech 1989). As an example, the hydrolytic stability of heterochiral RNA is reduced in comparison to that of the pure homochiral form (Urata et al. 2005). It can be supposed that the homochirality of RNA affords possibilities for the chiral selection of amino acids during 
the aminoacylation of nucleic acids, which is the first step of protein synthesis. Experiments with RNA constructs have shown that the $\alpha$-amino group of amino acids does not play any role in the chiral selection (Tamura and Schimmel 2006). These investigators supposed that the chiral preference of RNA constructs for L-amino acids depends on avoiding a sugar-pucker-sensitive steric clash between a pendant group of a base and the amino acid side chain.

The experimental work connected with the origin of homochirality has been addressed mainly to the chiral building blocks of biopolymers, for example, amino acids and sugars (Tranter 1985, and citations therein, 1987; Urata 1999; Hazen et al. 2001; Meierhenrich and Thiemann 2004; Urata et al. 2005; Nanita and Cooks 2006). Theoretical calculations of the parity violating energy differences (PVEDs) were used to explain the homochiral selection of monomeric biomolecules with small differences in the energy $\left(\Delta E_{\mathrm{PV}}\right)$ of enantiomers (Yamagata 1966; Hazen et al. 2001; Faglioni et al. 2005, and citations therein). Here, we present the first experimental evidence that RNA in the D-configuration has a different energy level scheme than the corresponding L-form, leading to an improved stability of the naturally occurring $\mathrm{D}$-configuration.

\section{RESULTS AND DISCUSSION}

We have analyzed the electronic energy levels associated with excitations of vibrations employing ultraviolet resonance Raman spectroscopy (Schulz et al. 2005) on the Dand L-enantiomers of an RNA duplex with the sequence [r(CUGGGCGG).r(CCGCCUGG)]. The sequence of this RNA fragment corresponds to domain $\mathrm{E}$ of Thermus flavus $5 \mathrm{~S}$ rRNA. The spectra obtained at excitation energies close to $5 \mathrm{eV}$ are near the absorption maxima of the free bases adenine, guanine, cytosine, and uracil. A difference between the Raman spectra of the two enantiomers was observed when changing the incident photon energy through the resonance level. Figure 1a shows spectra taken with incident photon energies (wavelength) $5.2094 \mathrm{eV}$ (238.1 $\mathrm{nm}), 5.0834 \mathrm{eV}(243.9 \mathrm{~nm})$, and $4.8205 \mathrm{eV}(257.2 \mathrm{~nm})$. The spectra were obtained from the $\mathrm{D}$ - and L-isomers for comparison. All measurements were done with three accumulations. The received spectra were identical for all accumulations, therefore no time dependence, and accordingly no effect of denaturation, was observed. Whereas the spectra of D- and L-RNA show hardly any difference for incident photon energy of $4.8205 \mathrm{eV}$, we observed significant differences in the spectra taken with $5.0834 \mathrm{eV}$ and $5.2094 \mathrm{eV}$. This difference is plotted as Raman difference spectra in Figure 1b. Differences in the intensity of the vibrational spectra were observed in the region between $124.0 \mathrm{meV}$ and $210.8 \mathrm{meV}$ with maxima at $186.0 \mathrm{meV}$, $192.2 \mathrm{meV}$, and $200.9 \mathrm{meV}$. Clearly, the spectra depend on the energy of the incident photons, and the intensity of the band changes with the wavelength of the excitation light.

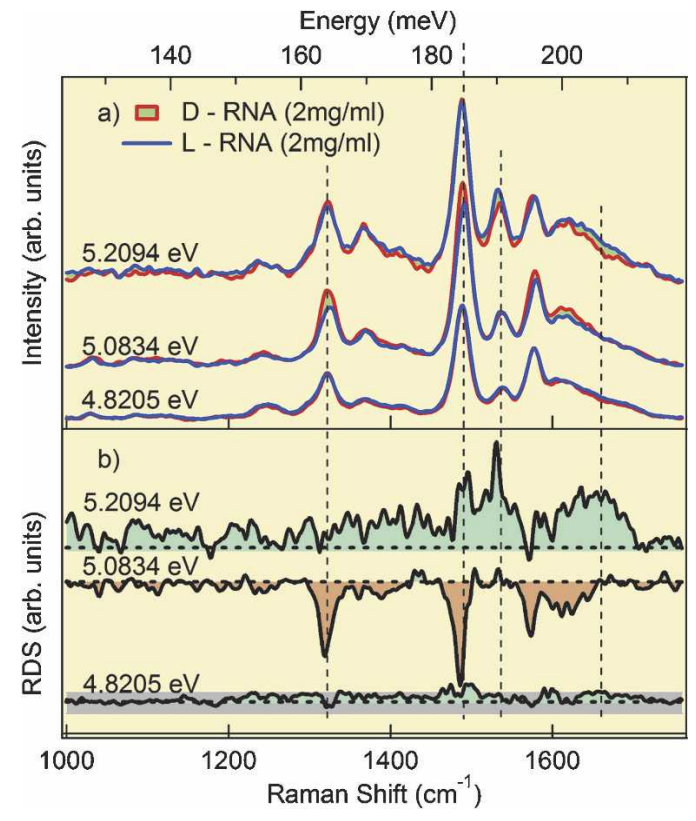

FIGURE 1. (a) Raman spectra of RNA duplexes in D- and Lconfiguration with the sequence [r(CUGGGCGG).r(CCGCCUGG)] at excitation wavelength of the incident photons of $5.2094 \mathrm{eV}, 5.0834$ $\mathrm{eV}$, and $4.8205 \mathrm{eV}$. Each spectrum corresponds to the median of three accumulations. (b) Difference spectra at incident photon energies of $5.2094 \mathrm{eV}, 5.0834 \mathrm{eV}$, and $4.8205 \mathrm{eV}$. The gray dotted background line, which is shown for the difference spectra at $4.8205 \mathrm{eV}$, demonstrates the size of the experimental error, valid and representative for all three measurements.

Figure 2a shows that resonance Raman scattering is a two-step process. An electronic transition creates a dipole moment, which is modulated by an elementary excitation such as a vibration. This implies that incoming light is absorbed by the electronic system. The coupling of the vibration and the electronic system of the molecule yields a scattered and frequency-shifted Raman line that is strongly dependent on the energy of the incident photons. This is due to the fact that the absorption varies strongly as a function of the incident energy. Therefore, differences in the intensities could be due to a different strength in the absorption or due to an energy difference of the electronic levels seen in the absorption process. However, both mechanisms can be discriminated, as shown in Figure 2, $\mathrm{b}$ and $\mathrm{c}$, by the fact that a change in the oscillator strength yields only a negative or positive difference in the difference spectra but never both. Due to the fact that we observe positive and negative difference spectra when subtracting L-D-RNA spectra, we can conclude that the electronic levels coupling the vibrational excitations are shifted in energy (Fig. 2d). The magnitude of the shift is in the order of a few millielectron volts, which is still several orders of magnitude larger than expected by theory (Faglioni et al. 2005). Assuming that the energy difference $\Delta E$ is at least in the order of a few millielectron volts, and taking into 
a)
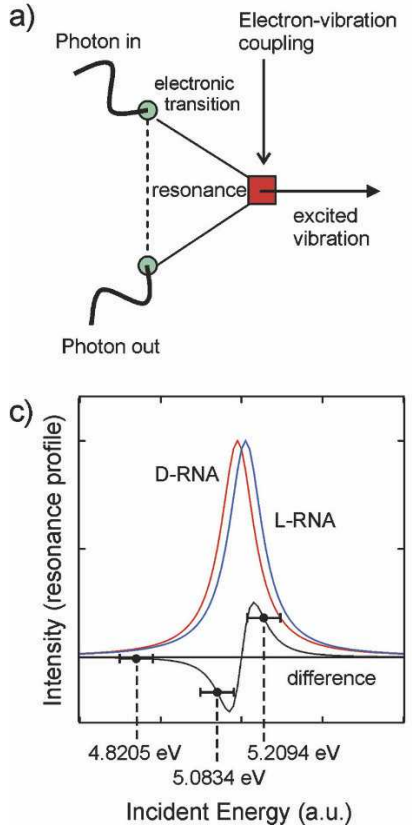

FIGURE 2. (a) Feynman-Graph of the resonance Raman process. Light is absorbed by the electronic system, which, in turn, couples to the vibrational system of a molecule. (b) Raman difference spectra when subtracting D-RNA from L-RNA, when the strength of the absorption process of the electric levels is different. (c) Intensity of the Raman difference spectra when the electronic levels are shifted in energy. The diagram shows the Resonance profiles of D-RNA (red) and L-RNA (blue) as a function of the incident photon energy. The points and their corresponding error bars indicate positions of the three measurements at $4.8205 \mathrm{eV}, 5.0834 \mathrm{eV}$, and $5.2094 \mathrm{eV}$. (d) Term scheme as a possible explanation of homochirality due to a shift in the energy levels between L-RNA and D-RNA.

account that the room temperature corresponds to an energy of $\sim 25 \mathrm{meV}$, it can be concluded that the energy difference clearly indicates an evolutionary preference of D- over L-RNA:

$$
\frac{N_{L}}{N_{D}} \propto \frac{1}{\exp \left(\frac{\Delta E}{k_{B} T}\right)} .
$$

This points toward the possibility that the different orientations of the base pairs in the RNA enantiomers have an effect on the electronic energy levels and correspondingly on the intensity of the vibrational Raman spectra.

The observed relatively large energy shift points toward a novel mechanism involving a strong coupling of the electronic energy levels with the vibrational system. This effect, even though being somewhat anticipated by theory, requires a significant modification of many calculations (Bonner 1999; Faglioni et al. 2005).

As was mentioned above, only theoretical calculations of PVEDs between enantiomers of amino acids and ribose were used for the explanation of the homochirality of biomolecules. Although the calculated values are exceedingly low, some investigators seem to accept that PVEDs are a valid reason for the observed homochirality (Kondepudi and Nelson 1985). For others (Bonner 1999), these differences are too small to promote a preferred chirality. In any case, so far there is no experimental confirmation of the theoretical calculations. This is the first study that provides experimental evidence at the macromolecular level that the D-enantiomer of RNA has a different energy level scheme from its counterpart in the L-configuration.

\section{MATERIALS AND METHODS}

\section{Synthesis of D- and L-enantiomers of an RNA duplex}

The oligoribonucleotides 5'-CUGGGCGG-3' and 5'-CCGCC UGG-3' have been synthesized in D- and L-configuration and purified as described previously (Perbandt et al. 2001; Vallazza et al. 2004). The D-RNA and the L-RNA helices were separately annealed (Perbandt et al. 2001), and HPLC analysis showed homogeneity of both samples.

\section{Raman spectroscopy}

Raman spectra were recorded with three accumulations using a custom-made UV resonance Raman spectrometer as described previously (Schulz et al. 2005). The instrument has an allreflective design and is set up in a clean room with constant temperature $\left(22.0^{\circ} \mathrm{C} \pm 0.5^{\circ} \mathrm{C}\right)$ and humidity $(40 \% \pm 3 \%)$. The samples were measured in water (concentration: $2 \mathrm{mg} / \mathrm{mL}$ ), in a cuvette with a Suprasil window under continuous mixing. The sample volume was $100 \mu \mathrm{L}$ in each case. The radiant flux of the incident laser beam was $\sim 1 \mathrm{~mW}$ for the applied excitation wavelengths, and the diameter of the beam and the focal depth were $15 \mu \mathrm{m}$. The illuminated volume of the sample was $2.7 \times 10^{-6} \mu \mathrm{L}$, which is only $2.7 \times 10^{-8}$ times the overall sample volume. In this way, a possible denaturation effect caused by the illumination was eliminated. The obtained spectra were background corrected and normalized to $1 \mathrm{~mW}$ power as well as to an integration time of $1 \mathrm{sec}$. Measurements with D- and L-RNA were done repeatedly at each of the three wavelengths, with equal acquisition times and identical photon power. The spectra show no time dependence, and moreover the applied mixing procedure provided a sufficient material exchange in the measured volume so that RNA material is continuously transported and exchanged in the sampling volume. The instrument was calibrated for its spectral response.

\section{ACKNOWLEDGMENTS}

We thank RiNA GmbH, Berlin, for the financial support; Stefan Vonhoff of NOXXON Pharma for providing the oligonucleotides; and M.V. Klein for discussions.

Received March 16, 2007; accepted August 3, 2007.

\section{REFERENCES}

Bonner, W.A. 1999. Enantioselective autocatalysis. V. The spontaneous resolution of tri-O-thymotide. Orig. Life Evol. Biosph. 29: $317-328$. 
Cech, T. 1989. Ribozyme self-replication? Nature 339: 507-508.

Cordova, A., Ibrahem, I., Casas, J., Sunden, H., Engqvist, M., and Reyes, E. 2005a. Amino acid catalyzed neogenesis of carbohydrates: A plausible ancient transformation. Chemistry 11: 4772-4784.

Cordova, A., Enqvist, M., Ibrahem, I., Casas, J., and Sunden, H. 2005b. Plausible origins of homochirality in the amino acid catalyzed neogenesis of carbohydrates. Chem. Commun. 20: 2047-2049.

Davankov, V. 2006. Chirality as an inherent general property of matter. Chirality 18: 459-461.

Faglioni, F., Passalacqua, A., and Lazzeretti, P. 2005. Parity violation energy of biomolecules. I: Polypeptides. Orig. Life Evol. Biosph. 35: 461-475.

Hazen, R., Filley, T., and Goodfriend, G. 2001. Selective adsorption of L- and D-amino acids on calcite: Implications for biochemical homochirality. Proc. Natl. Acad. Sci. 98: 5487-5490.

Kondepudi, D.K. and Nelson, G.W. 1985. Weak neutral currents and the origin of biomolecular chirality. Nature 314: 438-441.

Meierhenrich, U. and Thiemann, W. 2004. Photochemical concepts on the origin of biomolecular asymmetry. Orig. Life Evol. Biosph. 34: $111-121$

Nanita, S. and Cooks, R. 2006. Serine octamers: Cluster formation, reactions, and implications for biomolecule homochirality. Angew. Chem. Int. Ed. Engl. 45: 554-569.

Perbandt, M., Vallazza, M., Lippmann, C., Betzel, Ch., and Erdmann, V.A. 2001. Structure of an RNA duplex with an unusual G.C pair in wobble-like conformation at $1.6 \AA$ resolution. Acto Crystallogr. D Biol. Crystallogr. 57: 219-224.

Schulz, B., Bäckström, J., Budelmann, D., Maeser, R., Rübhausen, M., Klein, M.V., Schoeffel, E., Mihill, A., and Yoon, S. 2005. Fully reflective deep ultraviolet to near infrared spectrometer and entrance optics for resonance Raman spectroscopy. Rev. Sci. Instrum. 76: 1-12.

Tamura, K. and Schimmel, P.R. 2006. Chiral-selective aminoacylation of an RNA minihelix: Mechanistic features and chiral suppression. Proc. Natl. Acad. Sci. 103: 13750-13752.

Tranter, G.E. 1985. The parity violating energy differences between the enantiomers of $\alpha$-amino acids. Mol. Phys. 56: 825-838.

Tranter, G.E. 1987. The enantio-preferential stabilization of D-ribose from parity violation. Chem. Phys. Lett. 135: 279-282.

Urata, H. 1999. Effect of chirality of ribose on nucleic acid structure and function. Yakugaku Zasshi 119: 689-709.

Urata, H., Sasaki, R., Morita, H., Kusumoto, M., Ogawa, Y., Mitsuda, K., and Akagi, M. 2005. Kinetic analysis of hydrolytic reaction of homo- and heterochiral adenylyl $\left(3^{\prime}-5^{\prime}\right)$ adenosine isomers: Breaking homochirality reduces hydrolytic stability of RNA. Chem. Commun. 20: 2578-2580.

Vallazza, M., Perbandt, M., Klussmann, S., Rypniewski, W., Einspahr, H.M., Erdmann, V.A., and Betzel, Ch. 2004. First look at RNA in-L-configuration. Acta Crystallogr. D Biol. Crystallogr. 60: $1-7$.

Wolfrom, M., Lemieux, R., and Olin, S. 1949. Configurational correlation of L-(levo)-glyceraldehyde with natural (dextro)alanine by a direct chemical method. J. Am. Chem. Soc. 71: 2870-2873.

Yamagata, Y. 1966. A hypothesis for the asymmetric appearance of biomolecules on Earth. J. Theor. Biol. 11: 495-498.

Zaug, A. and Cech, T. 1986. The intervening sequence RNA of tetrahymena is an enzyme. Science 231: 470-475. 

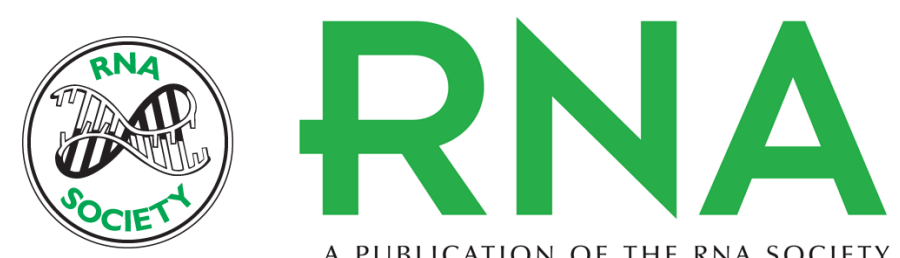

A PUBLICATION OF THE RNA SOCIETY

\section{First experimental evidence for the preferential stabilization of the natural D- over the nonnatural L-configuration in nucleic acids}

Sarah Bolik, Michael Rübhausen, Stephan Binder, et al.

RNA 2007 13: 1877-1880 originally published online September 5, 2007

Access the most recent version at doi:10.1261/rna.564507

\section{References This article cites 21 articles, 3 of which can be accessed free at: http://rnajournal.cshlp.org/content/13/11/1877.full.html\#ref-list-1}

License
Email Alerting Receive free email alerts when new articles cite this article - sign up in the box at the Service top right corner of the article or click here.

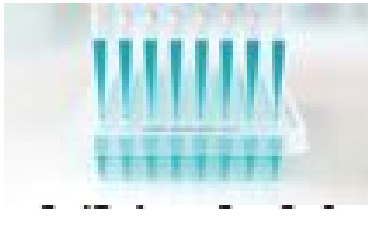

